\title{
The Health and Social Implications of Household Air Pollution and Respiratory Diseases
}

\author{
Mohit Bhardwaj, Ankit Aggarwal and Ayush Pandey \\ Department of Pulmonary Medicine Shree Guru Gobind Singh \\ Tricentary University, Gurugram, Haryana, India \\ Corresponding author email: bhardwajmohit007@rediff.com
}

\section{ABSTRACT}

The nature and human, both, have been suffering from the various type of the pollution. The one of the most adverse type of the pollution is air pollution. The air pollution has been categories in two broad terms as indoor air quality and outdoor air quality. The present paper has been written to address the problems associated with the household air problem. For the study purpose, some villages have selected in the Panipat district, where solid bio fuel used to cook the food.A simple questionnaire has prepared to discuss and notify the problem. In the district of the Panipat, 5villages have selected for the study and data has been collected after being granted an ethical permission to analysis the kitchen in the targeted house and sample of mean time for doing cooking work has been analyzed. The results have found that prolonged exposure to air pollution lead to many diseases such as respiratory problems, pulmonary problems and even cancer. Therefore, it is necessary to have a proper and well designed ventilation in the kitchen to avoid the risk of the diseases.

KEY WORDS: CHRONIC OBSTRUCTIVE PULMONARY DISEASE, COOKING FUELS, HOUSEHOLD AIR POLLUTION, SOLID BIO FUEL.

\section{INTRODUCTION}

The indoor air pollution is major cause of the chronic obstructive pulmonary disease (COPD). The indoor air pollution is the cause of the many respiratory problems along with some dermatological diseases. The fact is that afresh and clean air must be circulated within the wall of a house and house is also equipped with well ventilation in order to make available of a fresh air to breathe. If air is trapped within the wall of the house, itbecomescontaminated as the time passes and causes to many problem and unhygienic living condition of occupant of the particular house(M. J. chdwick et. al. (2019)). A type of the disease known as the sick building syndrome is the result of the contaminated

Biosc Biotech Res Comm P-ISSN: 0974-6455 E-ISSN: 2321-4007

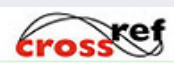

Identifiers and Pagination

Year: 2021 Vol: 14 No (6) Special Issue

Pages: $325-329$

This is an open access article under Creative

Commons License Attribn 4.0 Intl (CC-BY).

DOI: $h t t p: / / d x . d o i . o r g / 10.21786 / b b r c / 14.7 .69$ air. Many research outcomes revealed that sick building syndrome is due to the poor air quality and the main reason of the contamination is the biological factors such as molds, pollen and bacteria as well as viruses.

Fig.1 has been showing the different type of the indoor air pollutant .In urban area, the constructions of the house are so dense that most of the house equipped with an air duct to in and out of the air from any confined area, but with time the filters attached with these duct have contaminated and the quality of air can be improved with replaced the filters with news one. These are several other simple ways to enhance the quality of the air within any confined space; some ways adapted the changing the design of the space and some other ways adopts the precautionary measurement to be taken for avoid the contamination of the indoor air. Fig.2 has been showing the main disease due to air pollution $(\mathrm{H}$. Riojas-Rodríguez et. al. (2017).

The air pollution is the cause of much disease among the people; moreover, air pollution is very dangerous for the children, elderly people and pregnant women. The fig. 2 has been illustrating the type of disease which occurs due to air

\section{Article Information}

Received: $11^{\text {th }}$ May 2021

ccepted after revision: $14^{\text {th }}$ July 2021 
pollution. In NCR (National Capital region), air quality has become very low in winter session and air quality index has been marked as high as 500 .The main reason of the air pollution is the burning of the waste of crops in the Punjab, Haryana and Uttar Pradesh ( et. al. (20)). The low temperature of the winter is also play its part to keep the pollution particle suspended in the air. The suspended particle with moist air goes directly inside the lung of the human and causes same severe problems. The experts revealed that it has been estimated that a human inhale the polluted air as much as equal to 10 cigarette smoke in such weather.

Figure 1: Different Type of Indoor Air Pollution

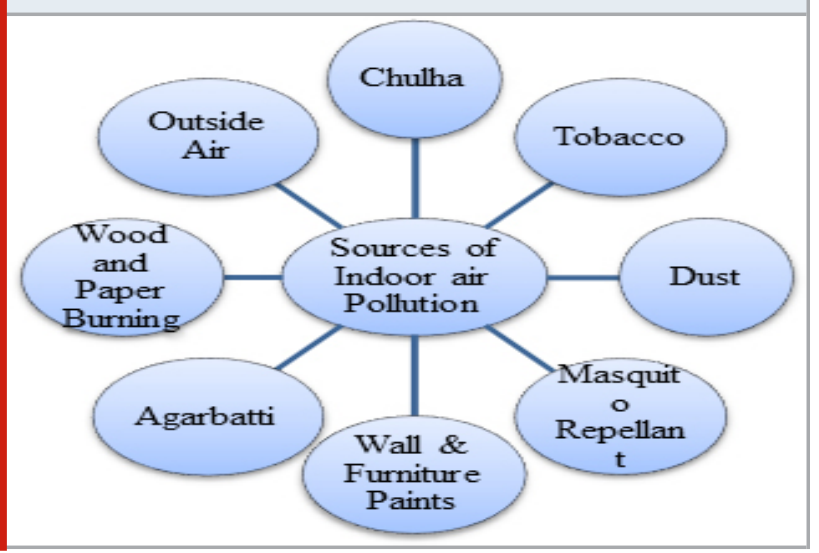

Figure 2: Disease Due To Air Pollution

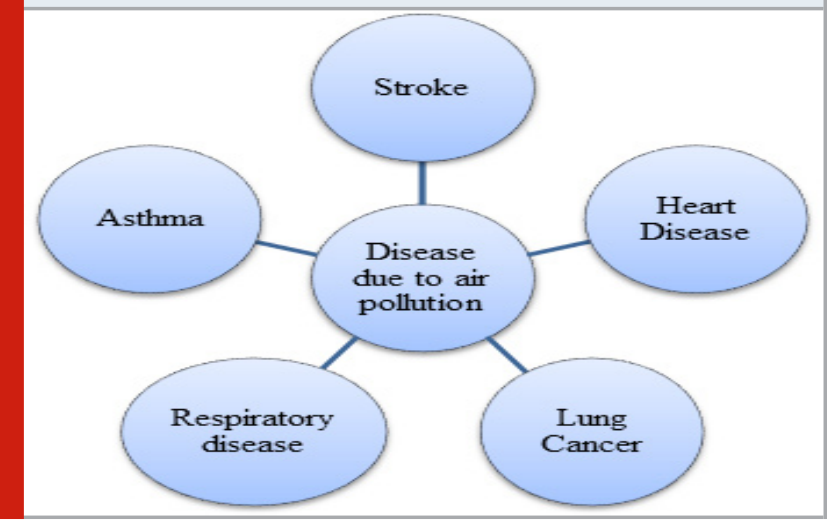

Review Of Literature: Chadwick, M. J. has revealed thatair emissions have harmful effects immediately on the environment itself, both on living both inert objects by subsequent deposition from the environment. Significant local indoor emission effects may be present in direct combustion using biomass for heating, cooking and illumination(World Health Organization et. al. (2016)). All essential factors that should be considered are the size of environmental consequences, the degree to which agents cause damage, and the interactions between the source of the pollutant and the features of transport as well as diffusion that deliver it to the atmospheric sink where the transmitter agents are located. The magnitude of environmental impacts arising from the use of biomass fuels varies from local to regional, national, continental to global impacts. Gaseous contaminants conduct electricity metals; they lose surface roughness, and their properties can be changed. In fact, the comparatively straightforward idea of a source of contaminants, connected to a sink made up of receptors that can be adversely impacted by transport as well as diffusion, is loaded with complications (D. Y. C. Leung et. al. (20).

WHO media centre has revealed that a major burden on people's wellbeing and the ecosystem the use of enclosed, two-stone fire pits in resource-poor nations. In rural areas, a national intervention was conducted to encourage the purchase including the use of an enhanced cooking stove. The objectives of this qualitative research were to understand the incentive to buy and use; the potential advantages and challenges of using cookstove; and the most relevant advertising activities for scaling up the marketing of potential cookstove. In order to attract cookstove promoters including cookstove consumers in the tribal culture, sampling technique was used. Semi - structure interviews have been transcribed and a thematic review carried out(F. W. S. Ko et. al. (2012)). As major advantages of the cooking stove, participants reported any need for less wood chips, fuel cost savings, decreased smoke, enhanced cooking efficiency, reduced eye irritation, lung inflammation and coughing. Cost seemed to constitute an obstacle to broader acceptance. Interpersonal contact via social networks including cooking demonstrations was the most convincing promotion strategies. Despite these cost barriers, the improved cooking stove was still considered by many women to be a valuable addition within their household. This investigation provided substantial guidance for potential projects to incorporate the cookstove (A. Luengas et. al. (2015).

\section{METHODOLOGY}

1. Design: A common consensus has been created between the data collector and house owner in order to get the data from the each house. A number of village and city have been selected to conduct the study. An ethical clearance has also been taken from the Sarpanch of the respective village(A. Luengas et. al. (2015)). For the study of the data, an authoritative permission has been taken from the district administration. After receiving appropriate authoritative ethical,a selection of houses has been done to evaluate the air pollution coming out of the from the kitchen of respective houses.

2. Sample: For the sample some village of the Panipat district had selected. Panipat is district of the Haryana state of the India. The Panipat is located at $29.39^{\circ} \mathrm{N} 76.97^{\circ} \mathrm{E}$ and situated at an elevation of the 219 meters from the sea level. The 5 village have selected for the study. The study need to enter in the house of an individual, therefore, it is important to have the permission of the district administration along with the written permission of the sarpanch of the each village before seeking the permission from the owner of the respective house (S. A. Ahmed Abdul-Wahab et. al. (2015).

Apart from this, some houses have selected at the town and in the city near to the selected village in order to include them in the survey which having the different type of design 
of the kitchen to be included in the study. A questionnaire session also have developed to assesses the view of the villager on the air pollution that is continuously a cause to deteriorate their health and the villagers are enough aware that the air pollution is also a slow poison that willaffect their health badly. Fig. 3 has been showing the geographic allocation of the Panipat(J. M. Seguel et. al. (2017).

3. Instrument: A cross examination method has been implemented to check the data. The survey has been conducted with an intention to collect the data as to determine the kitchen type, stove types as well as fuel type(J. Taylor et. al. (2016)). Apart from this a questionnaire session has been conducted with the member of the family which had been chosen for the survey.

Figure 3: Geographic Allocation of the Panipat

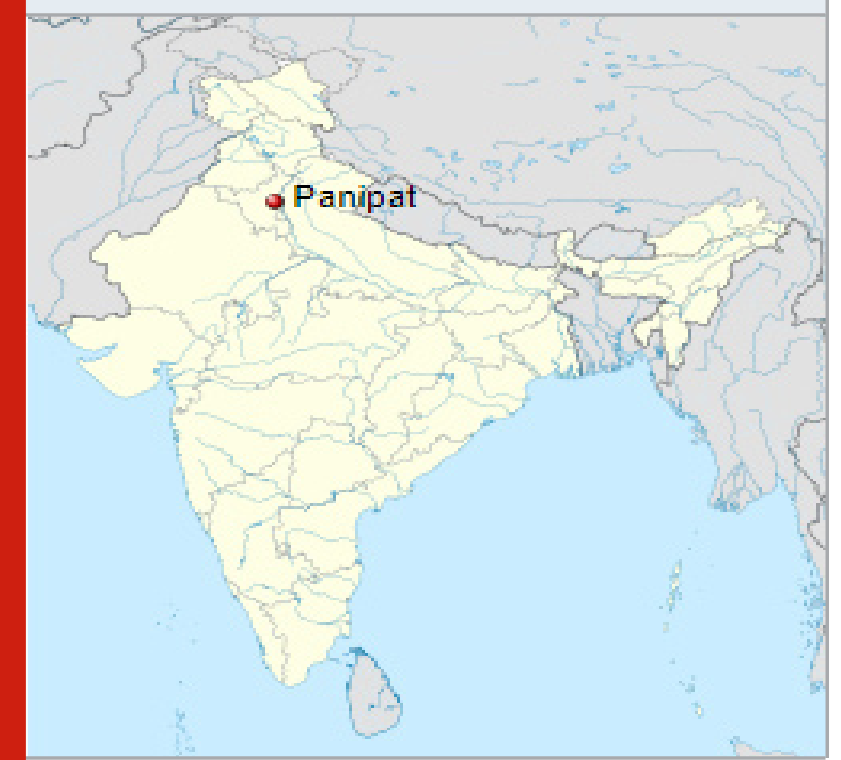

4. Data collection: The most of the house hold in the districtof Panipat at rural area uses the solid bio fuels to cook their food. The survey conducted by the national sample survey organization revealed that more than 90 percentage of the house hold in rural area use the solid bio fuel to meet their cooking requirement and it is found that Punjab and Haryana are the leading state to use the solid bio fuelfor the cooking purpose. The sample size has kept at 100 strictly. The type of the kitchen found in these localities different from each other and their categorization have been given below(Fig.4):

1. Indoor Kitchen with no Partition

2. Indoor Kitchen with Partition

3. Outdoors Enclosed Kitchen

4. Outdoors open air Kitchen

5. Outdoor Semi-open air Kitchen

\section{Data Analysis:}

5.1. Household air quality monitoring: The important place in every house to measure the air quality is the kitchen of that particular house. The parameters for the quality check foe the air inside the kitchen is the aerosol, PM2.5 and PM10 along with the relative humidity and generation of the carbon mono oxide ( $\mathrm{CO}$ ). the presence of the aerosol has been measured with the help of the DUSTTRAK, which is a aerosol monitor instrument, the model used is the 8520 and procured from a company from the California USA. And PM2.5 identified with the QTRAKTM, which also a monitor instrument for the indoor air value.

\section{Figure 4: Different Type of Design of the Houses}

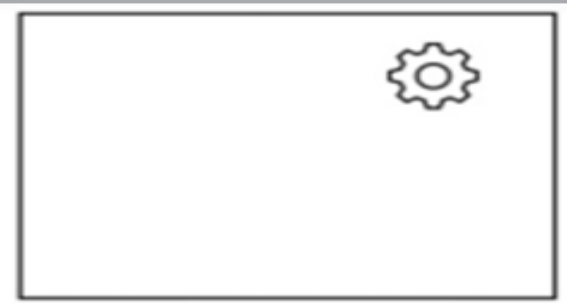

(a) Indoor Kitchen With no partition

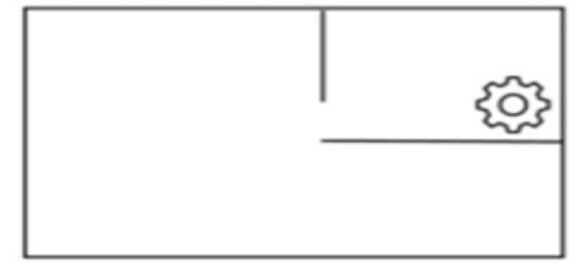

\section{(b) Indoor Kitchen with Partition}

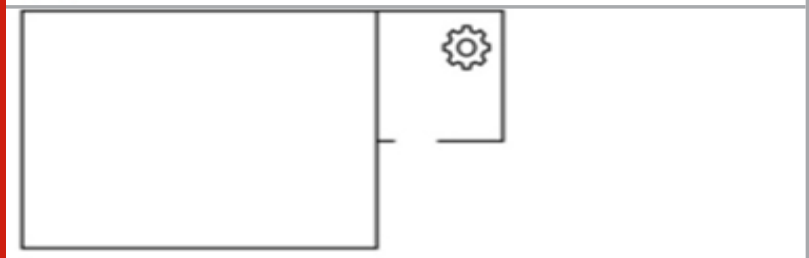

(c) Outdoor Enclosed Kitchen
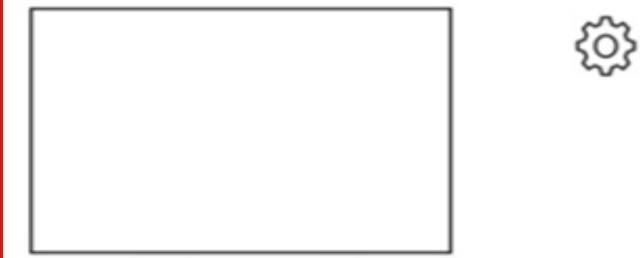

(d) Outdoor Open Kitchen

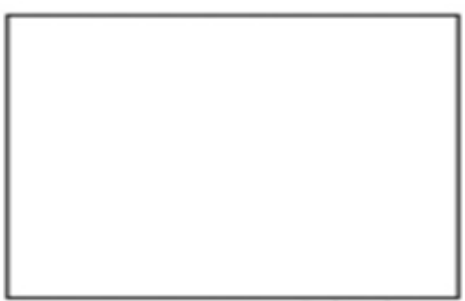

(e) Outdoor Semi Open Kitchen 
The reading has been captured for the 24 hours with a 10 $\mathrm{s}$ time interval. The instrument are capable to measure the particle size of the 0.1 to $10 \mu \mathrm{m}$ and range can varied between the $0.001-100 \mathrm{mg} / \mathrm{m} 3$. Until monitoring, the PM2.5 sampler was set to zero and, during each sampling, the impactor plate was adequately greased to prevent any dust particles within the inlet and to eliminate particle bouncing(T. Chang et. al. (2016)). Consequently, a limited quantity of Krytox vacuum grease has been used to supply the instrument.

\subsection{Exposure assessment}

5.2.1. Development of PM2.5 exposure index: The PM2.5 developed during the cooking process with the help of the fuel various type of the fuel. As stated before, the most common fuel is the solid bio fuel in the targeted region of the survey has been conducted. The 24 hours time has been fixed to calculate and identified the presence of the $P M$ 2.5. The main aim of the investigation is to find out the generation, propagation and movement of the PM 2.5 particles after it came in the environment.

5.2.2. Intake concentration: A number of mechanisms have been identified to find the effect of the air pollutant on the human body. The human can expose by ingestion, inhalation or even dermal absorption. The present study has been conducted to find out the adverse effect on the human body but still main aim to find the impact on the health of the women, because in the rural area women is responsible for the all the house hold work and most of the time she remain within the four wall of the house. Moreover, women is responsible for the all cooking work and dusting work of the house apart from the responsible for the care of the domestic animal up to some extent(S. A. Ahmed AbdulWahab et. al. (2015)). To find out the exposure assessment, the mean exposure time spent in the Kitchen and cooking work has been calculated on the basis of the recalling of the time of the individual women of the each house. It is evident that long term of the exposure to the air pollutant is a reason of the chronic Obstructive Pulmonary disease (COPD) and other related respiratory diseases.

5.2.3. Toxicological risk: The health impact of air pollutants which exceed the permissible limits rely strongly on the dosage of the pollutant. PM2.5 inhalation can cause significant acute and chronic health risks. Mostly during cooking cycle, inhalation of $\mathrm{CO}$ increases the levels of carboxyl hemoglobin and breathing $\mathrm{CO}$, which may contribute to a high incidence of symptoms of $\mathrm{CO}$ toxicity. $\mathrm{CO}$, nevertheless, is not really a human carcinogen, but perhaps the cardiovascular system is considered to be affected. The WHO guideline values were therefore used more as a standard concentration to determine the hazard quotient for PM2.5. The toxicological risk of exposure to PM2.5 was therefore calculated as a hazard coefficient determined by the ratio between the intake concentration and the comparison concentration.

\section{RESULTS AND DISCUSSION}

The study found that the health related issues are more with the women who spent more time in the cooking process.
Thereis much variation in the type of the kitchen found in these areas as some have the kitchen within the boundary of the house with no proper ventilation and some have the proper ventilation but kitchen is still situated inside the house and some have the kitchen outside the house but with a enclosure and even some villagers have the kitchen in total open space without any enclosure(G. Liu et. al. (2017)).As per the kitchen design,exposures of the women with the air pollutant have varied and consequently, their exposure to the pollutant is a deciding factor to have a check on the health of the women.

The one more problemwith house design is that somehouse in these localities is made of the cement and concrete and some of the made of the mud. The houses made of the concrete and cement are the pucca type of the house and they have problem of the stick of the pollutant with the wall of the house and over the time, when thickness of the layer have increased, some germs and bacteria will take birth and cause the biological factor to pollute the air (B. R. Barnes et. al. (2014)). The house lady is more vulnerable to the risk of the house hold air pollutant because they spend considerable time in house hold and cooking process inside the house. The common disease have been given in below table which have been occurred because of the exposure for a prolong time in household air pollution.
1. Acute respiratory infections
2. Tuberculosis
3. Asthma
4. Chronic obstructive pulmonary disease (COPD)
5. Pneumoconiosis
6. Head and neck cancer
7. Lung cancer

\section{CONCLUSION}

The most significant source of indoor air pollution is smoke generated from converting biomass fuel combustion, which is commonly used for heating and cooking in residential villages and poor neighborhoods in India. The association of indoor air pollution with substantial morbidity and mortality through cardio-respiratory disorders, including congestive heart failure, asthma, respiratory infections, aspiration pneumonia, and lung cancer, is clearly illustrated by a plethora of studies from developing countries and emerging economies. The effect of various cook-stove modifications to minimise household air pollution exposure is very minimal, resulting in no risk mitigation for diseases. Only large-scale replacement of solids with renewable energy such as cooking gas, as has been tried in India there under Pradhan MantriUjjwalaYojna, may accomplish the degree of reductions needed for beneficial effects.

\section{REFERENCES}

Abdul-Wahab, S.A., En, S.C.F., Elkamel, A., Ahmadi, L. and Yetilmezsoy, K., 2015. A review of standards and guidelines set by international bodies for the parameters of indoor air quality. Atmospheric Pollution Research, 6(5), pp.751-767.

Barnes, B.R., 2014. Behavioural change, indoor air 
pollution and child respiratory health in developing countries: a review. International journal of environmental research and public health, 11(5), pp.4607-4618.

Chang, T., Graff Zivin, J., Gross, T. and Neidell, M., 2016.

Particulate pollution and the productivity of pear packers. American Economic Journal: Economic Policy, 8(3), pp.141-69.

Khan, M.N., Islam, M.M., Islam, M.R. and Rahman, M.M., 2017. Household air pollution from cooking and risk of adverse health and birth outcomes in Bangladesh: a nationwide population-based study. Environmental Health, 16(1), pp.1-8.

Ko, F.W. and Hui, D.S., 2012. Air pollution and chronic obstructive pulmonary disease. Respirology, 17(3), pp.395-401.

Leung, D.Y., 2015. Outdoor-indoor air pollution in urban environment: challenges and opportunity. Frontiers in Environmental Science, 2, p.69.

Liu, G., Xiao, M., Zhang, X., Gal, C., Chen, X., Liu, L., Pan, S., Wu, J., Tang, L. and Clements-Croome, D., 2017. A review of air filtration technologies for sustainable and healthy building ventilation. Sustainable cities and society, 32, pp.375-396.

Luengas, A., Barona, A., Hort, C., Gallastegui, G., Platel, V. and Elias, A., 2015. A review of indoor air treatment technologies. Reviews in Environmental Science and Bio/ Technology, 14(3), pp.499-522.
Pasztor, J. ed., 2019. Bioenergy and the Environment. Routledge.

Riojas-Rodríguez, H., Romieu, I. and Hernández-Ávila, M., 2017. In the mid-20th century, dramatic episodes of outdoor (ambient) air pollution in high-income countries demonstrated that air pollution could cause many deaths. For example, in the London Fog of 1952, during which there were high con-centrations of smoke from coal-burning house-hold stoves, an estimated 12,000 excess deaths occurred. The proportion of deaths due to res-piratory causes was increased. Infants, young. Occupational and Environmental Health: Recognizing and Preventing Disease and Injury, p.345.

Seguel, J.M., Merrill, R., Seguel, D. and Campagna, A.C., 2017. Indoor air quality. American journal of lifestyle medicine, 11(4), pp.284-295.

Taylor, J., Davies, M., Mavrogianni, A., Shrubsole, C., Hamilton, I., Das, P., Jones, B., Oikonomou, E. and Biddulph, P., 2016. Mapping indoor overheating and air pollution risk modification across Great Britain: A modelling study. Building and Environment, 99, pp.112.

Venkata Pavan, M., Karnan, B. and Latchoumi, T.P., 2021. PLA-Cu reinforced composite filament: Preparation and flexural property printed at different machining conditions. Advanced Composite Materials, https://doi. org/10.1080/09243046.2021, 1918608. 